\title{
Effect of forest bathing and exercising on human healthy in young people in Sichuan Province.
}

\author{
Mu He", Weiquan Guo\#, Qiongying Hu, Min Chen, Xiaohua Wang, Wei Xu, Sa Ma, Li Zhang, Qunfang \\ Lan, Jian Yang, Jihua Lan, Kailai Li, Qunying Chen, Wenjun Su*
}

Forestry Center Hospital, Sichuan Province, P.R. China

\#These author contribute equally to this work

\begin{abstract}
Objective: The aim of this article was to comprehensively examine the effect of forest bathing and exercising on human healthy in young people between forest and city environment in Sichuan province Methods: All experiments were randomly assigned to three groups. After doing experimental schedule which was informed to all the experiments, we summarized and analyzed the data of the experiences about physiological and psychological testing, such as blood testing containing Superoxide Dismutase (SOD), Tumor Necrosis Factor (TNF-a), Insulin-Like Growth Factor (IGF), psychological measurements including POMS and PANAS, and so on.

Results: Forest bathing might help to prevent cancer by IGF. Meanwhile reducing the level of oxidation in the body, it might achieve anti-aging, anti-tumor, and regulate the body's endocrine system to improve immunity. Forest bathing could significantly improve the mood and stress of the population, which reducing negative stress or negative emotions and increasing positive or positive emotions, to change the sub-health status of the population.

Conclusion: In this paper, we learned that forest bathing might be good at human health, especially on anti-aging, anti-tumor, regulation of human endocrine system, improvement of immunity, etc.
\end{abstract}

Keywords: Forest bathing, Human health, Forest environment, City environment.

Accepted on April 29, 2019

\section{Introduction}

Because of the quiet atmosphere, beautiful scenery, mild climate, and clean fresh air, the forest environment has been enjoyed by humans for a long leisure time. As human society becomes increasingly urbanized, various physiological and psychological diseases are caused by stress, thus affecting humans well-being and health [1,2]. Researchers in Japan have tried to find preventive effects against lifestyle-related diseases from forests and have proposed a new concept called "forest bathing". This is a short leisurely visit to a forest called "Shinrin-yoku" in Japanese, being similar in effect to natural aromatherapy, for the purpose of relaxation [3-5]. Forest bathing refers to visiting a forest or engaging in various therapeutic activities in a forest environment to improve one's health and wellbeing [6,7]. To improve health and well-being, many studies have investigated various relaxation approaches such as yoga, massage, meditation, green attractions, and forest bathing which is recognized relaxation and/or stress management activity and a method of preventing diseases and promoting health is becoming a focus of public attention by walking and observing in a forest [8-16].
Physiological studies support that forest bathing has positive effects on the central nervous, autonomic nervous and endocrine systems [17-22]. Forest-related activity can increase human immune function by facilitating the activity of NK cells and anticancer proteins by immunology researches [23,24]. Meanwhile, clinical trials prove that forest bathing programs can be effective for hypertension and non-insulin-dependent diabetic patients $[25,26]$. In addition, human beings having emotional affiliation to forest environments, which is effective for stress reduction, depression alleviation, and psychological relaxation, are demonstrated by psychological studies [27-31]. Several studies have determined that being in a forest environment has health benefits; participants in such an environment have lower pulse rates and diastolic and systolic blood pressures [8,9,22,32-34,35-39] than in urban settings. The effect of forest visits on mental health has also been investigated in studies that have applied the Profile of Mood States (POMS) and determined that forest experiences increase positive emotions and reduce negative mood states $[9,33,40-45]$ in comparison with urban stimuli.

To this end, there are no researches about influence of forest bathing in Sichuan province which is hometown of panda. Based on the findings mentioned above, we speculate that 
walking in a forest environment may have beneficial effects on human being. Thus, in the our study, we investigate the effects of walking in a forest which is provided by the Mountain Qiqu Area and in the city to measure the physiological and psychological effects of forest bathing on young volunteers.

\section{Material and Methods}

\section{Experiments}

First 18 experiments who met certain inclusion criteria were recruited through a notice in the hospital, by phone or by email. Of these experiments were finally included in this study. Subjects all gave voluntary informed consent prior to the beginning of the study. Potential participants who were taking medication for chronic conditions such as diabetes, hyperlipidaemia, and hypertension were excluded. All experiments were fully informed of the aims and procedures of this experiment, and their informed consent was obtained prior to the experiment.

\section{Study sites}

All experiments were randomly assigned to three groups which named normal group (all situated in the city), control group (all situated in the forest), test group (all situated in the forest and had some exercise). We conducted the experiments in two areas of Sichuan province from 17 to 21 July, 2017. The forest environment (located near the towns of Zitong, which was near the city of Mianyang) as experimental field including control group and test group and the urban environments which including normal group located in the city of Chengdu, a captain of Sichuan province. Figure 1 shows the location of each environment.

\section{Experimental design}

The experimental schedule for this study is shown in Figure 2. On the day before testing, all the experiments were fully informed about the experimental procedure; blood from each experiment was sampled in the morning before breakfast, and the samples were tested in the clinical laboratory by technicians. To control for environmental conditions, the same living situation was prepared as lodgings for each group, and the same meals were offered during the experiments.

The experiments were allowed to do as they wished in normal group which was in the city environment. The same as that was in control group which was in the forest environment. The experiments in test group were required that walked along at an unhurried pace for about $1 \mathrm{~h}$, with a 15 minute rest during the walk and sit in the forest environment quietly for about 30 minutes. In the afternoon, after taking lunch in the resting room, the experiments were allowed to repeat the course which they did in morning again. All experiments were required to avoid strenuous exercise and any stimulating activities in their hours of relaxation before sleeping. The experiments were living at each experimental site for four days. In the morning before breakfast all groups were phlebotomized at the first day, the third day and the fifth day during the study and blood was sampled for tests in the clinical laboratory by technicians.

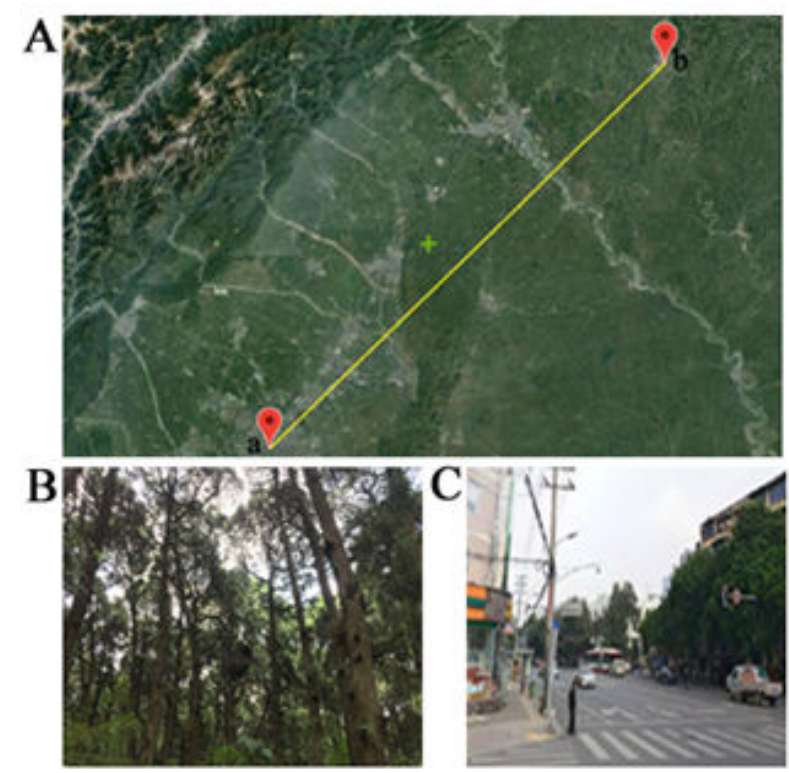

Figure 1. The location and environment of two experiment base, $A$ The location of two area in this experiment in Sichuan province. (A) base located in the city of Chengdu and b base located in Qiqu mountain which was near the city of Mianyang. (B) and (C) show the environment of the two experiment base.

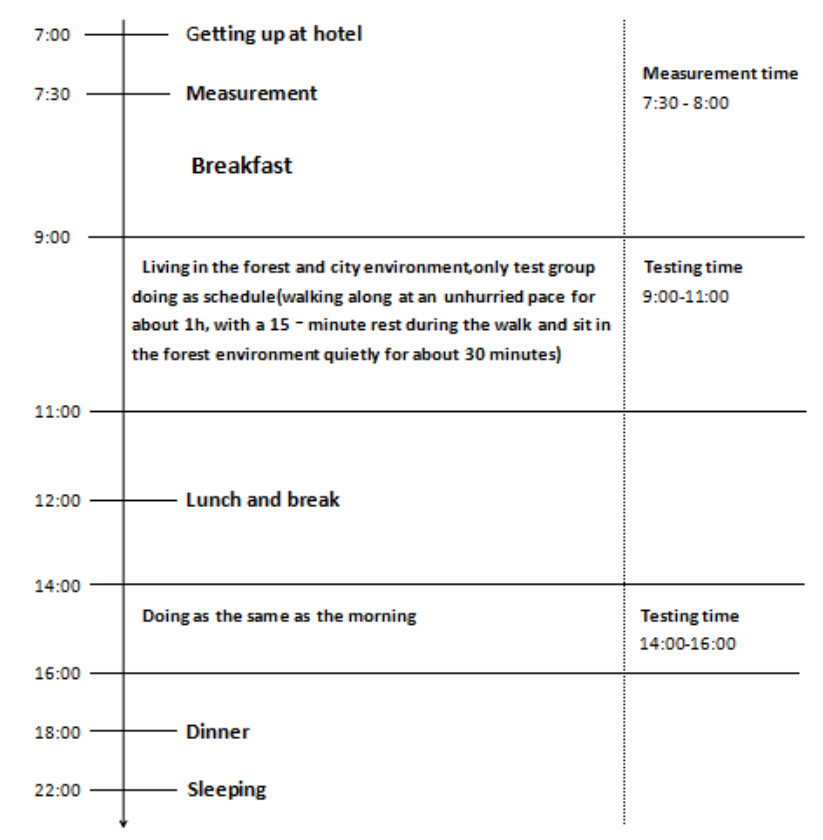

Figure 2. The experimental schedule for test group of this study.

\section{Psychological measurement}

Psychological measurements were used by POMS and PANAS. The Profile of Mood States (POMS) was used to gauge the psychological response. The POMS scores were determined for the following six subscales: "Tension-Anxiety (T-A)", "Confusion (C)", “Anger-Hostility (A-H)", 
"Depression (D)", "Fatigue (F)" and "vigor (V)". A short form of the POMS with 30 questions was used to decrease the burden on the subjects $[46,47]$. The Positive and Negative Affect Schedule (PANAS) $[48,49]$ measures the positive affect and negative affect using 20 items (10 each for positive and negative affect). The scales were shown to be highly internally consistent, largely uncorrelated and stable at appropriate levels over a two-month period [48]. All data were collected three times when phlebotomizing.

\section{Analysis methods}

All data are printed as mean \pm standard deviation. Data were analyzed using one-way analysis of variance. $P$ values of less than 0.05 were considered significant.

\section{Results}

\section{Baseline characteristics of experiments}

Eighteen experiments (age $21.94 \pm 2.83$ years, $\mathrm{P}=0.001^{* * *}$ ) participated as study subjects. Basic indicators, such as Body Mass Index (BMI), Blood Pressure (BP), and Heart Rate (HR), were not significantly different between the three groups. In addition, no significant differences in baseline values of biological indicators - including TNF- $\alpha$, SOD, cortisol and the distribution of leukocyte subsets-were observed between the three groups (Table 1).

Table 1. Data of baseline characteristics of experiments, the results were expressed as mean \pm standard deviation. All data were expressed as mean \pm standard deviation and were analyzed by One-Way ANOVA $\left({ }^{*} P<0.05,{ }^{* *} P<0.01,{ }^{* * *} P<0.005\right)$.

\begin{tabular}{|c|c|c|c|c|c|}
\hline & Total & Normal Group & Control group & Test group & P-value \\
\hline Sex (F\%) & $55.56 \%$ & $66.67 \%$ & $50.00 \%$ & $50.00 \%$ & 0.827 \\
\hline Age (y) & $21.94 \pm 2.83$ & $26.17 \pm 2.89$ & $19.67 \pm 1.33$ & $20.00 \pm 1.00$ & $0.001^{* * *}$ \\
\hline BMI & $20.26 \pm 1.73$ & $20.15 \pm 1.93$ & $18.97 \pm 0.58$ & $21.65 \pm 2.32$ & 0.136 \\
\hline SBP (mmHg) & $106.89 \pm 10.77$ & $100.67 \pm 8.67$ & $106.17 \pm 9.50$ & $113.83 \pm 13.83$ & 0.224 \\
\hline $\mathrm{DBP}(\mathrm{mmHg})$ & $74.06 \pm 4.62$ & $69.50 \pm 4.17$ & $75.50 \pm 4.83$ & $77.17 \pm 4.22$ & 0.117 \\
\hline MAP (mmHg) & $85.00 \pm 6.22$ & $79.89 \pm 5.67$ & $85.72 \pm 5.30$ & $89.39 \pm 7.17$ & 0.131 \\
\hline HR (times/min) & $73.89 \pm 10.47$ & $80.17 \pm 9.78$ & $70.00 \pm 8.33$ & $71.50 \pm 9.83$ & 0.363 \\
\hline TNF-a (pg/ml) & $24.23 \pm 14.25$ & $29.34 \pm 5.66$ & $26.95 \pm 15.63$ & $16.38 \pm 1.92$ & 0.611 \\
\hline $\mathrm{SOD}(\mathrm{U} / \mathrm{ml})$ & $151.52 \pm 4.26$ & $151.23 \pm 4.92$ & $149.33 \pm 7.82$ & $154.00 \pm 4.02$ & 0.399 \\
\hline Cortisol (ug/dl) & $17.82 \pm 2.12$ & $15.89 \pm 3.85$ & $19.13 \pm 1.25$ & $18.45 \pm 1.42$ & 0.089 \\
\hline IGF (ng/ml) & $292.39 \pm 33.61$ & $292.33 \pm 40.75$ & $289.00 \pm 47.35$ & $295.83 \pm 40.78$ & 0.963 \\
\hline WBC ( $\left.{ }^{*} 10^{9} / L\right)$ & $6.07 \pm 1.04$ & $5.05 \pm 0.53$ & $6.18 \pm 0.75$ & $6.30 \pm 1.10$ & 0.098 \\
\hline LYM (*109/L) & $2.05 \pm 0.66$ & $1.72 \pm 0.26$ & $2.66 \pm 0.52$ & $2.81 \pm 0.64$ & 0.196 \\
\hline RBC $\left({ }^{*} 10^{12} / L\right)$ & $4.77 \pm 0.33$ & $4.63 \pm 0.33$ & $4.91 \pm 0.46$ & $4.78 \pm 0.21$ & 0.526 \\
\hline HGB (g/L) & $142.67 \pm 11.89$ & $137.67 \pm 12.67$ & $147.83 \pm 14.78$ & $142.50 \pm 8.50$ & 0.535 \\
\hline
\end{tabular}

\section{Effect of forest bathing on anti-aging with superoxide dismutase}

Subjects staying forest area showed a decreased SOD level-an indicator of lipid peroxidation in the serum-compared with normal group and control group (Figure 3). Meanwhile, obvious change in the activity of SOD was significantly observed. The change of level of haemoglobin was irregular.

\section{Effect of forest bathing on stress response}

Cortisol level has been used as a stress marker in various scientific fields. In our research, we confirmed that the serum cortisol level was significantly lower in test group than that in normal group and control group (Figure 4). These findings indicated that experiments staying in a forest environment showed a reduced stress response.

\section{Effect of forest bathing on inflammation}

As shown in Figure 5, the TNF-a level was significantly reduced in test group compared with normal group and control group. Meanwhile the level of white cell and the level of lymphocyte were also reduced in test group compared with normal group and control group, but it was not significant. Reduced levels of inflammatory index indicated that forest bathing could exert a lower inflammatory response, which might change pathological conditions. 
A

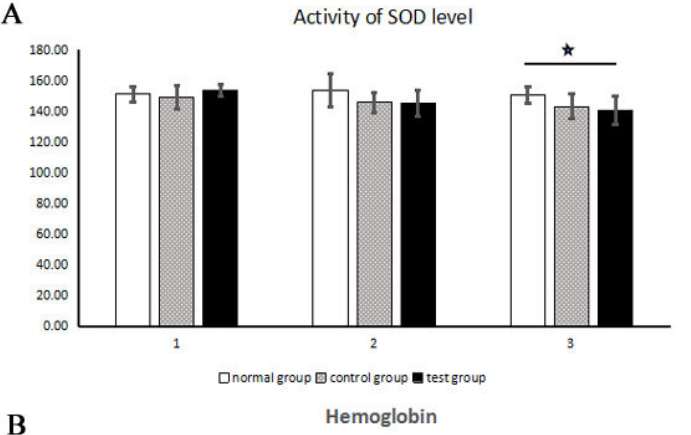

B

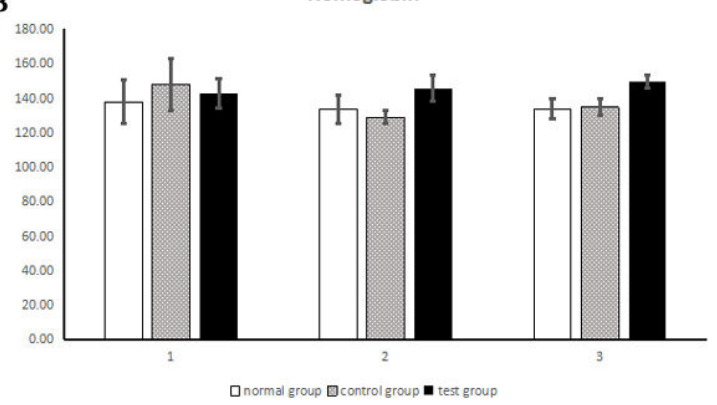

Figure 3. The results of data of anti-aging, A the data of superoxide dismutase, $B$ the data of haemoglobin, the results were expressed as mean \pm standard deviation. All data were expressed as mean \pm standard deviation and were analyzed by One-Way ANOVA $\left({ }^{*} P<0.05\right.$, $\left.{ }^{* *} P<0.01,{ }^{* * *} P<0.005\right)$.

\section{Effect of forest bathing on anti-tumor}

IGF had been used as a marker which was related to tumor in our study. In our research, we confirmed that the IGF level was significantly lower in test group than that in normal group (Figure 6). These findings indicated that people staying in a forest environment might reduce the probability of tumorigenesis.

\section{The level of cortisol}

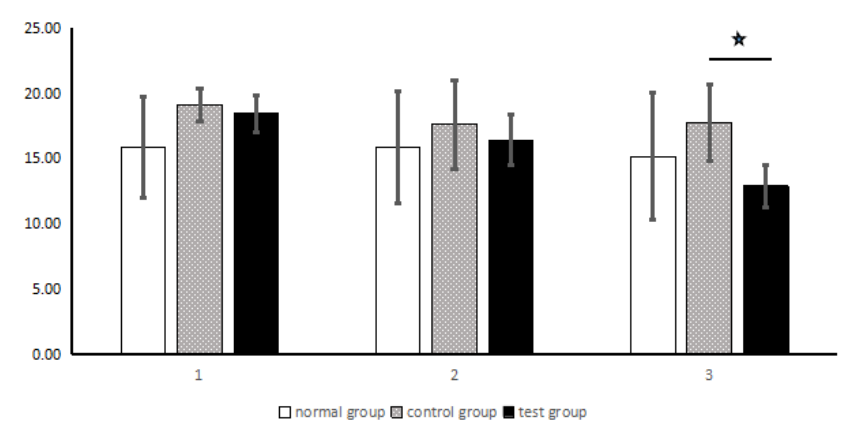

Figure 4. The results of data of cortisol level, The results were expressed as mean \pm standard deviation. All data were expressed as mean \pm standard deviation and were analyzed by One-Way ANOVA $\left({ }^{*} P<0.05,{ }^{* *} P<0.01,{ }^{* * *} P<0.005\right)$.
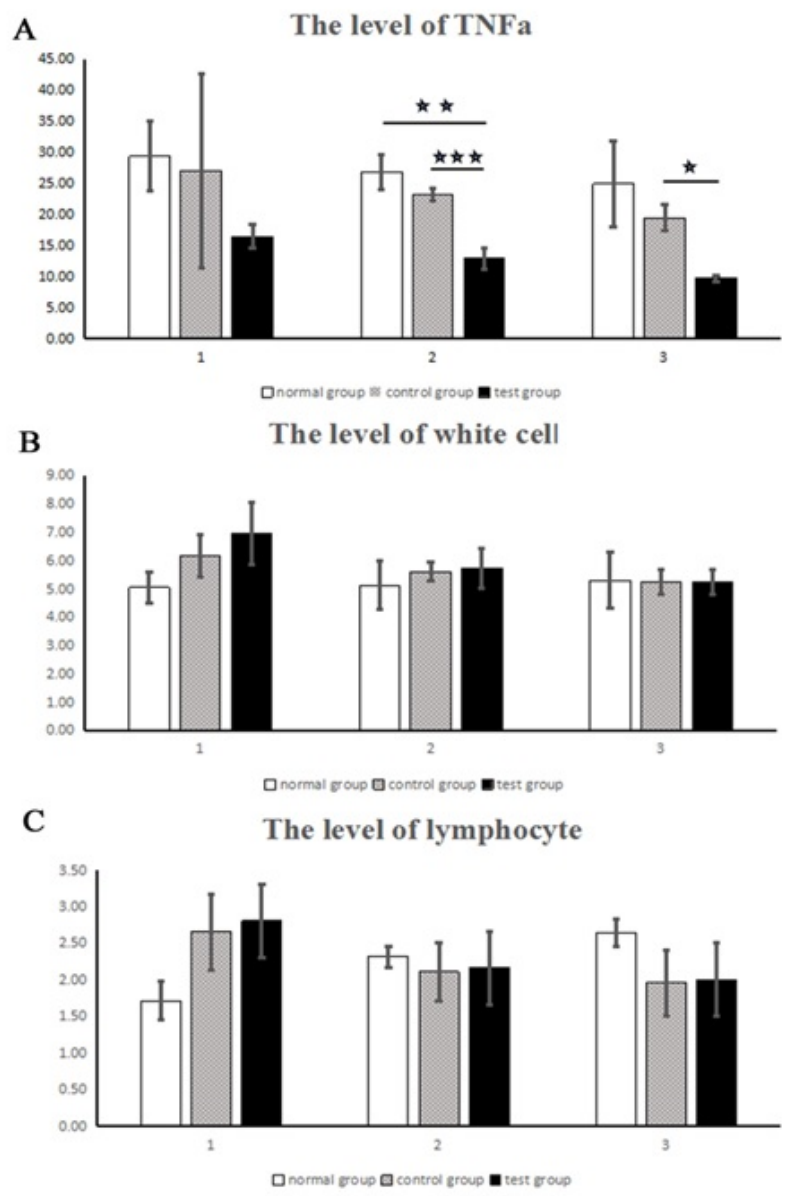

Figure 5. The results of data of inflammation, A. the data of level of TNF among three groups in our study, B. the data of level of white cell among three groups in our study, C. The data of level of lymphocyte among three groups in our study. The results were expressed as mean \pm standard deviation. All data were expressed as mean \pm standard deviation and were analyzed by One-Way ANOVA $\left({ }^{*} P<0.05,{ }^{* *} P<0.01,{ }^{* * *} P<0.005\right)$.

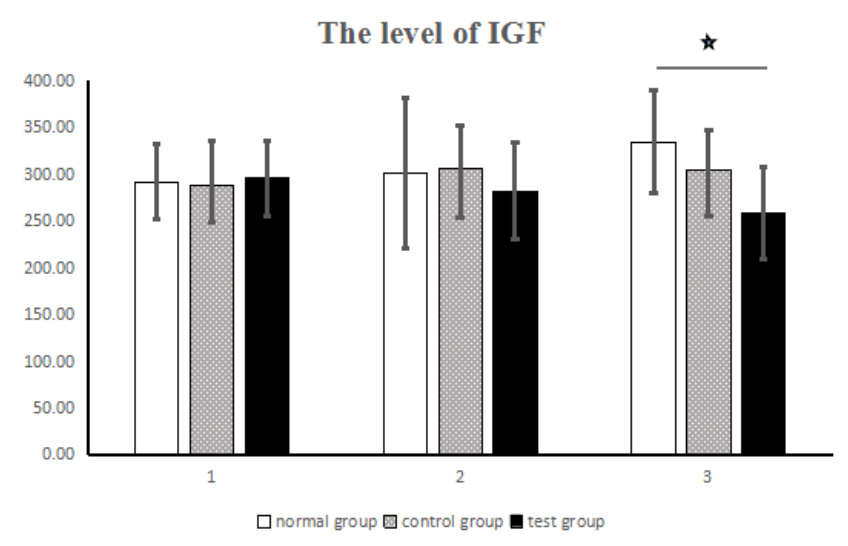

Figure 6. The results of data of IGF level, the results were expressed as mean \pm standard deviation. All data were expressed as mean \pm standard deviation and were analyzed by One-Way ANOVA $\left(^{*} P<0.05\right.$, $\left.{ }^{* *} P<0.01,{ }^{* * *} P<0.005\right)$. 


\section{Effect of forest bathing on mood state evaluation}

Most of the POMS and PANAS scores revealed significant improvements after the forest bathing (Figure 7). Five of the negative subscales of the POMS, "tension-anxiety", "angerhostility", "fatigue-inertia". "depression-dejection", and "confusion-bewilderment", decreased from pre-test to posttest. Conversely, the positive mood state "vigor-activity" significantly increased. Meanwhile the score of positive emotion had significantly increased in test group compared with others and the score of negative emotion had significantly decreased in test group.

A A Positive emotions

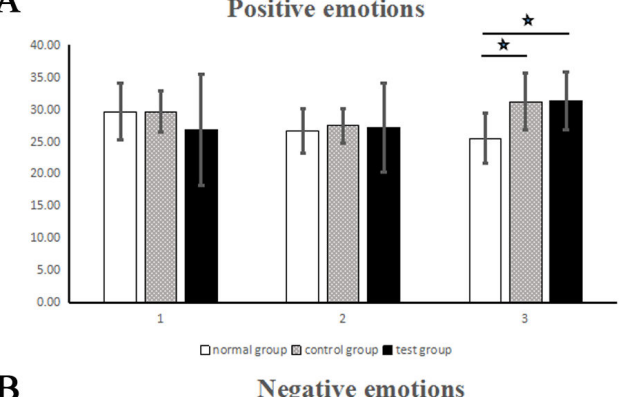

B

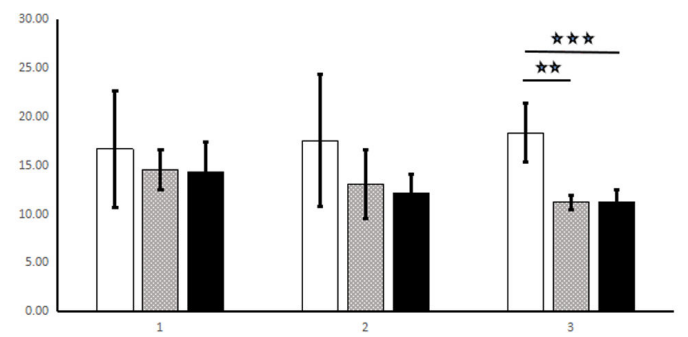

C

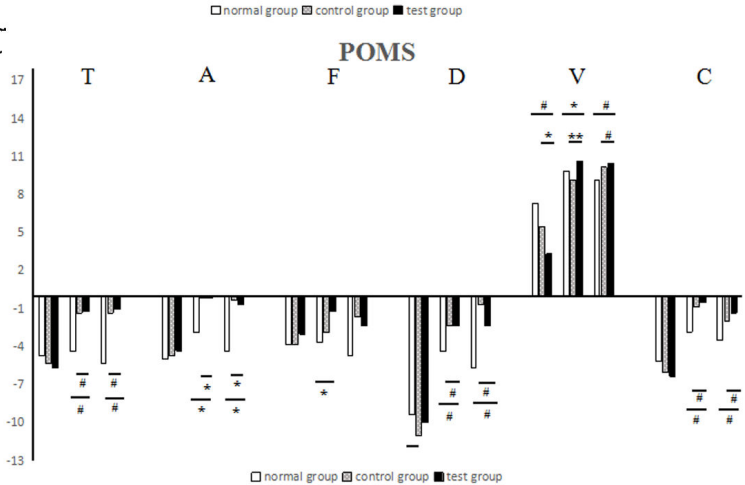

Figure 7. The results of scores of mood by PANAS and POMS, A. the result of scores of positive emotion by PANAS, $B$. the result of scores of negative emotion by PANAS, $C$. The results of scores of mood by POMS, The results were expressed as mean \pm standard deviation. All data were expressed as mean \pm standard deviation and were analyzed by One-Way ANOVA $\left({ }^{*} P<0.05,{ }^{* *} P<0.01,{ }^{\#} P<0.005\right)$.

\section{Discussion}

In modern society, pollution is an unavoidable problem, especially in many developing countries. It has been reported that chronic exposure to urban air pollution produces inflammation in rodents. Elevated levels of inflammatory mediator gene expression, including interleukin-1 $\beta$ (IL-1 $\beta$ ),
IL-6, and TNF- $\alpha$, were observed in mice exposed to polluted areas compared with those kept in clean air [50,51]. As is well known, the air in a forest environment is much cleaner than in an urban area. Thus, our results of a reduced inflammatory response in experiments who were exposed in a forest environment compared with that in a city area is consistent with the results of that previous study [52,53]. Air pollution is thought to exert negative health effects through oxidative stress, which causes damage to DNA and lipids. Exposure to inhaled emissions can induce oxidized LDL and vascular reactive oxygen species in both humans and rodents $[53,54]$. In our research, we have provided indirect evidence that forest bathing is beneficial for reducing oxidative stress in humans. Based on our results, people who were exposure to forest environments were a way to reduce inflammatory reactions and oxidative stress by the level of TNF-a and SOD and thus might help to promote health. It is believed that higher levels of negative oxygen ions are beneficial for human health. Performance efficiency and mental state being improved by exposure to negative ions in the environment were shown by investigations into physiological and psychological conditions [51,53]. Thus, we speculated that the beneficial effect of forests for humans might be at least partly due to the abundance of negative air ions; however we couldn't get the data of levels of negative oxygen ions in this research. Several previous studies have also demonstrated that forest bathing enhances immune functions. It has been reported that subjects who took a three-day trip to a forest area showed enhanced immune functions, as evidenced by an increase in Natural Killer (NK) cell activity and the levels of intracellular granulysin, perforin, and granzymes A and B [23,24,51]. In our study, decreased level of TNF-a in forest environment might be benefit for inflammation of human compared with that living in city area. Lucky we also found that the level of IGF had decreased in test group (forest environment) compared to that in normal group (city environment). The insulin like growth factor 1 (IGF-1) and its receptor (IGF-1R) facilitate tumor proliferation and progression [54]. The findings in our research might reveal that in forest environment for short-term could reduce the incidence of tumors. Modern societies are subject to high stress owing to the fast pace of life. In addition, people living in urban areas are prone to irritability and tiredness through being in a crowded, unpleasant environment that is characterized by noisy traffic and the unpleasant smells of automobile exhausts. This was consistent with that of a previous study, which used the salivary cortisol level as a stress marker [7,51]. In addition, experiments that were staying in the forest environment felt more comfortable, such as score of tension, depression, anger, fatigue, and confusion in POMS test, were lower than those of the normal group and control group, and the score for vigor was elevated. So we confirmed that people living in forest environment might improve their mood and feel comfortable compared to who living in the city environment. However, the present study was limited in some areas. First, the outcomes might need to be repeated in larger experiments because of the limited sample size in our research. Second, it is not known whether our findings in young healthy participants would be reflected in other aged individuals. 
Third, we lacked of the factor of climate in our study. We choose July in this study because it was a suitable season for outdoor travel in our country and we could avoid rainy day for safe, but it might be a little hot.

\section{Conclusion}

Our study has provided some evidences that living and exercising in a forest environment, even for a short time, carries out benefits on human health. In addition, forest bathing may mean a potential medical care in several pathology, including inflammation, tumor, hormone and nervous conditions. We intend to hold on some studies on experiments of different ages and even examine the detailed molecular mechanisms in some animals which were regarding the relationship between forest bathing and the effects on human health.

\section{References}

1. Dye C. Health and urban living. Science. 2008; 319: 766-769.

2. Wagner KH, Brath H. A global view on the development of non-communicable diseases. Prev Med. 2012; 54: S38S41.

3. Li Q, Morimoto K, Nakadai A, Inagaki H, Katsumata M, Shimizu T, Hirata Y, Hirata K, Suzuki H, Miyazaki Y, Kagawa T, Koyama Y, Ohira T, Takayama N, Krensky AM, Kawada T. Forest bathing enhances human natural killer activity and expression of anti-cancer proteins. Int $\mathrm{J}$ Immunopathol Pharmacol. 2007; 20: 3-8.

4. Li Q. Forest Medicine. In: Li Q, editor. Forest Medicine. New York, NY, USA: Nova Science Publishers; 2012: 1-316.

5. Li Q, Kobayashi M, Kumeda S, Ochiai T, Miura T, Kagawa T, Imai M, Wang Z, Otsuka T, Kawada T. Effects of Forest Bathing on Cardiovascular and Metabolic Parameters in Middle-Aged Males. Evid Based Complement Alternat Med 2016; 2016: 2587381.

6. Li Q. Forest Medicine. Nova Science Publisher; New York, NY, USA: 2013. What is forest medicine? p. 3-10.

7. Park BJ, Tsunetsugu Y, Kasetani T, Hirano H, Kagawa T, Sato M, Miyazaki Y. Physiological effects of shinrin-yoku (taking in the atmosphere of the forest)-Using salivary cortisol and cerebral activity as indicators. J Physiol Anthropol 2007; 26: 123-128.

8. Lee J, Park BJ, Tsunetsugu Y, Kagawa T, Miyazaki Y. Restorative effects of viewing real forest landscapes, based on a comparison with urban landscapes. Scand. J For Res 2009; 24: 227-234.

9. Lee J, Park BJ, Tsunetsugu Y, Ohira T, Kagawa T, Miyazaki Y. Effect of forest bathing on physiological and psychological responses in young Japanese male subjects. Public Health 2011; 125: 93-100.

10. Li Q. Effect of forest bathing trips on human immune function. Environ Health Prev Med 2010; 15: 9-17.
11. Morita E, Fukuda S, Nagano J, Hamajima N, Yamamoto H, Iwai $Y$, Nakashima $T$, Ohira H, Shirakawa T. Psychological effects of forest environments on healthy adults: Shinrin-yoku (forest-air bathing, walking) as a possible method of stress reduction. Public Health. 2007; 121: 54-63.

12. Im SG, Choi H, Jeon YH, Song MK, Kim W, Woo JM. Comparison of effect of two-hour exposure to forest and urban environments on cytokine, anti-oxidant, and stress levels in young adults. Int $\mathrm{J}$ Environ Res Public Health 2016; 13: 625

13. Igarashi M, Aga M, Ikei H, Namekawa T, Miyazaki Y. Physiological and psychological effects on high school students of viewing real and artificial pansies. Int J Environ Res Public Health 2015; 12: 2521-2531.

14. Igarashi M, Miwa M, Ikei H, Song C, Takagaki M, Miyazaki Y. Physiological and psychological effects of viewing a kiwifruit (Actinidia deliciosa 'hayward') orchard landscape in summer in Japan. Int J Environ Res Public Health 2015; 12: 6657-6668.

15. Shapiro D, Cook IA, Davydov DM, Ottaviani C, Leuchter AF, Abrams M. Yoga as a complementary treatment of depression: Effects of traits and moods on treatment outcome. Evid Based Complement Altern Med 2007; 4: 493-502.

16. Delaney J, Leong KS, Watkins A, Brodie D. The shortterm effects of myofascial trigger point massage therapy on cardiac autonomic tone in healthy subjects. J Adv Nurs 2002; 37: 364-371.

17. Lee J, Park BJ, Tsunetsugu Y, Kagawa T, Miyazaki Y. Restorative effects of viewing real forest landscapes, based on a comparison with urban landscapes. Scand J Forest Res 2009; 24: 227-234.

18. Lee J, Park BJ, Tsunetsugu Y, Ohira T, Kagawa T, Miyazaki Y. Effect of forest bathing on physiological and psychological responses in young Japanese male subjects. Public Health 2011; 125: 93-100.

19. Lee J, Park BJ, Tsunetsugu Y, Miyazaki Y. Forests and human health-recent trends in Japan. In: Li Q, editor. Forest Medicine. 1st edition. New York, NY, USA: Nova Science; 2012: 243-257.

20. Matsunaga K, Park B-J, Kobayashi H, Miyazaki Y. Physiologically relaxing effect of a hospital rooftop forest on older women requiring care. J Am Geriatr Soc. 2011; 59: 2162-2163.

21. Park BJ, Tsunetsugu Y, Kasetani T, Kagawa T, Miyazaki Y. Physiological effects of Shinrin-yoku (taking in the atmosphere of the forest)-using salivary cortisol and cerebral activity as indicators. J Physiol Anthropol 2007; 26: 123-128.

22. Tsunetsugu Y, Park BJ, Ishii H, Hirano H, Kagawa T, Miyazaki Y. Physiological effects of Shinrin-yoku (taking in the atmosphere of the forest) in an old-growth broadleaf forest in Yamagata Prefecture, Japan. J Physiol Anthropol 2007; 26: 135-142. 
23. Li Q, Morimoto $\mathrm{K}$, Nakadai A Inagaki H, Katsumata M, Shimizu T, Hirata Y, Hirata K, Suzuki H, Miyazaki Y, Kagawa T, Koyama Y, Ohira T, Takayama N, Krensky AM, Kawada T. Forest bathing enhances human natural killer activity and expression of anti-cancer proteins. Int $\mathrm{J}$ Immunopathol Pharmacol 2007; 20: 3-8.

24. Li Q, Morimoto K, Kobayashi M, Inagaki H, Katsumata M, Hirata Y, Hirata K, Shimizu T, Li YJ, Wakayama Y, Kawada T, Ohira T, Takayama N, Kagawa T, Miyazaki Y. A forest bathing trip increases human natural killer activity and expression of anti-cancer proteins in female subjects. J Biol Regul Homeost Agents 2008; 22: 45-55.

25. Sung J, Woo JM, Kim W, Lim SK, Chung EJ. The effect of cognitive behavior therapy-based "forest therapy" program on blood pressure, salivary cortisol level, and quality of life in elderly hypertensive patients. Clin Exp Hypertens 2012; 34: 1-7.

26. Ohtsuka Y, Yabunaka N, Takayama S. Shinrin-Yoku P (Forest-air bathing and walking) effectively decreases blood glucose levels in diabetic patients. Int $\mathrm{J}$ Biometeorol 1998; 41: 125-127.

27. Wilson EO. Biophilia the human bond with other species. Cambridge, Mass, USA: Harvard University Press; 1984.

28. Kaplan R, Kaplan S. The experience of nature: A psychological perspective. Cambridge, UK: Cambridge University Press; 1989.

29. Ulrich RS, Simons RF, Losito BD, Fiorito E, Miles MA, Zelson M. Stress recovery during exposure to natural and urban environments. J Environ Psychol 1991; 11: 201-230.

30. Morita E, Fukuda S, Nagano J, Hamajima N, Yamamoto $H$, Iwai $Y$, Nakashima $T$, Ohira $H$, Shirakawa $T$. Psychological effects of forest environments on healthy adults: Shinrin-Yoku (forest-air bathing, walking) as a possible method of stress reduction. Public Health 2007; 121: 54-63.

31. Shin WS. The influence of forest view through a window on job satisfaction and job stress. Scand J Forest Res 2007; 22: 248-253.

32. Li Q, Otsuka T, Kobayashi M, Wakayama Y, Inagaki H, Katsumata M, Hirata Y, Li Y, Hirata K, Shimizu T. Acute effects of walking in forest environments on cardiovascular and metabolic parameters. Eur J Appl Physiol 2011; 111: 2845-2853.

33. Park BJ, Tsunetsugu Y, Kasetani T, Kagawa T, Miyazaki Y. The physiological effects of shinrin-yoku (taking in the forest atmosphere or forest bathing): Evidence from field experiments in 24 forests across Japan. Environ Health Prev Med 2010; 15: 18-26.

34. Park BJ, Tsunetsugu Y, Kasetani T, Morikawa T, Kagawa T, Miyazaki Y. Physiological effects of forest recreation in a young conifer forest in Hinokage town, Japan. Silva Fennica 2009; 43: 291-301.

35. Tsunetsugu Y, Lee J, Park BJ, Tyrväinen L, Kagawa T, Miyazaki Y. Physiological and psychological effects of viewing urban forest landscapes assessed by multiple measurements. Landsc Urban Plan 2013; 113: 90-93.

36. Park BJ, Tsunetsugu Y, Ishii H, Furuhashi S, Hirano H, Kagawa T, Miyazaki Y. Physiological effects of shinrinyoku (taking in the atmosphere of the forest) in a mixed forest in Shinano town, Japan. Scand J For Res 2008; 23: 278-283.

37. Mao GX, Cao YB, Lan XG, He ZH, Chen ZM, Wang YZ, $\mathrm{Hu}$ XL, Lv YD, Wang GF, Yan J. Therapeutic effect of forest bathing on human hypertension in the elderly. J Cardiol 2012; 60: 495-502.

38. Song C, Ikei H, Miyazaki Y. Elucidation of a physiological adjustment effect in a forest environment: A pilot study. Int J Environ Res Public Health 2015; 12: 4247-4255.

39. Park BJ, Furuya K, Kasetani T, Takayama N, Kagawa T, Miyazaki Y. Relationship between psychological responses and physical environments in forest settings. Landsc Urban Plan 2011; 102: 24-32.

40. Tsunetsugu Y, Park B, Lee J, Kagawa T, Miyazaki Y. Psychological relaxation effect of forest therapy: Results of field experiments in 19 forests in Japan involving 228 participants. Jpn J Hyg 2011; 66: 670-676.

41. Horiuchi M, Endo J, Akatsuka S, Uno T, Hasegawa T, Seko Y. Influence of forest walking on blood pressure, profile of mood states, and stress markers from the viewpoint of aging. J Aging Gerontol 2013; 1: 9-17.

42. Ochiai H, Ikei H, Song C, Kobayashi M, Miura T, Kagawa T, Li Q, Kumeda S, Imai M, Miyazaki Y. Physiological and psychological effects of a forest therapy program on middle-aged females. Int $\mathrm{J}$ Environ Res Public Health 2015; 12: 15222-15232.

43. Ochiai H, Ikei H, Song C, Kobayashi M, Takamatsu A, Miura T, Kagawa T, Li Q, Kumeda S, Imai M. Physiological and psychological effects of forest therapy on middle-aged males with high-normal blood pressure. Int J Environ Res Public Health 2015; 12: 2532-2542.

44. Song C, Ikei H, Igarashi M, Miwa M, Takagaki M, Miyazaki Y. Physiological and psychological responses of young males during spring-time walks in urban parks. J Physio Anthropol 2014; 33: 8.

45. Song C, Joung D, Ikei H, Igarashi M, Aga M, Park BJ, Miwa M, Takagaki M, Miyazaki Y. Physiological and psychological effects of walking on young males in urban parks in winter. J Physiol Anthropol 2013; 32: 18.

46. Yokoyama K, Araki S, Kawakami N, Takeshita T. Production of the Japanese edition of profile of mood states (POMS): assessment of reliability and validity (in Japanese). Jpn J Public Health 1990; 37: 913-918.

47. McNair DM, Lorr M. Droppleman LF. Profile of mood states Manual; Educational and Industrial Testing Service: San Diego, CA, USA, 1992.

48. Watson D, Clark, LA, Carey G. Positive and negative affectivity and their relation to anxiety and depressive disorders. J Abnorm Psychol 1988; 97: 346-353. 
49. Watson D, Clark LA, Tellegen A. Development and validation of brief measures of positive and negative affect: The PANAS scales. J Pers Soc Psychol 1988; 54: 1063-1070.

50. Villarreal-Calderon R, Reed W, Palacios-Moreno J, Keefe S, Herritt L, Brooks D, Torres-Jardón R, CalderónGarcidueñas L. Urban air pollution produces upregulation of myocardial inflammatory genes and dark chocolate provides cardioprotection. Exp Toxicol Pathol, 2012; 64: 297-306.

51. Xiang MG, Guang LX, Bao CY, Chem ZM, He ZH, Lv YD, Wang YZ, Hu XL, Wang GF, Yan J. Effects of ShortTerm Forest Bathing on Human Health in a Broad-Leaved Evergreen Forest in Zhejiang Province, China. Biomed Environ Sci 2012; 25: 317-324.

52. Lund AK, Lucero J, Harman M, Madden MC, McDonald JD, Seagrave JC, Campen MJ. The oxidized low-density lipoprotein receptor mediates vascular effects of inhaled vehicle emissions. Am J Respir Crit Care Med 2011; 184: 82-91.
53. Ryushi T, Kita I, Sakurai T, Yasumatsu M, Isokawa M, Aihara Y, Hama K. The effect of exposure to negative air ions on the recovery of physiological responses after moderate endurance exercise. Int J Biometeorol 1998; 41: 132-136.

54. Wang H, Su X, Fang J, Xin X, Zhao X, Gaur U, Wen Q, $\mathrm{Xu}$ J, Little PJ, Zheng W. Tanshinone IIA Attenuates Insulin Like Growth Factor 1 -Induced Cell Proliferation in PC12 Cells through the PI3K/Akt and MEK/ERK Pathways. Int J Mol Sci 2018; 19: 2719.

\section{*Correspondence to}

Wenjun $\mathrm{Su}$

Forestry Centre Hospital

Sichuan Province

P.R. China 